\title{
Reflection Characteristics of a Near-Interface Cavity in Ice at Supercritical Incidence
}

\author{
Wen-Kai Wang, ${ }^{1,2,3}$ Guang-Ping Zhu $\mathbb{D}^{1,}{ }^{1,2,3}$ Jing-Wei Yin, ${ }^{1,2,3}$ and Hui Sun ${ }^{1,2,3}$ \\ ${ }^{1}$ Acoustic Science and Technology Laboratory, Harbin Engineering University, Harbin 150001, China \\ ${ }^{2}$ Key Laboratory of Marine Information Acquisition and Security (Harbin Engineering University), \\ Ministry of Industry and Information Technology, Harbin 150001, China \\ ${ }^{3}$ College of Underwater Acoustic Engineering, Harbin Engineering University, Harbin 150001, China
}

Correspondence should be addressed to Guang-Ping Zhu; e5-2670@outlook.com

Received 10 February 2019; Accepted 8 May 2019; Published 29 May 2019

Academic Editor: Lukasz Pieczonka

Copyright (C) 2019 Wen-Kai Wang et al. This is an open access article distributed under the Creative Commons Attribution License, which permits unrestricted use, distribution, and reproduction in any medium, provided the original work is properly cited.

The long-range propagation modes in an acoustic channel under ice are basically caused by supercritical incidence. The energy distribution and transmission loss in the acoustic channel under ice are changed by a scatter in ice. The influence of a slender cylindrical cavity near and parallel to the ice-water interface on the sound propagation is analyzed using Fourier-Bessel series and Sommerfeld-Watson transformation. The research found that the acoustic field presents a beam in the mirror reflection direction at supercritical incidence, and the beam-width is proportional to secant of incident angle; meanwhile, the reflected coefficient is proportional to cosine of incident angle. The reflection coefficient increases with relative depth and Helmholtz number if the incident angle is a constant.

\section{Introduction}

The Arctic region has important strategic significance and commercial value. The sound propagation characteristics in an acoustic channel under ice depend on the parameters of the ice canopy, which has a noticeable influence on the acoustic navigation and communication under ice $[1,2]$. The ice canopy in current researches was considered as an ideal elastic layer on the macro scale, or its reflection coefficient was obtained through experiments to calculate the transmission loss, but the influence of microstructure in ice on the acoustic channel under ice has not been considered yet. The microstructure changes not only the attenuation of sound wave in the original propagation direction but also the spatial distribution of acoustic energy under ice. Therefore, it is of great significance to study the influence of microstructures in ice on the sound propagation characteristics in an acoustic channel under ice.

Acoustic experimental researches in the Arctic region can be traced back to the last century [3]. The ice area, climate, and earthquakes were monitored through the experimental data of underwater acoustic propagation $[4,5]$. The ice canopy has an influence on the transmission loss in an acoustic channel under ice, and the transmission loss at different depths might exceed 10dB [6], but the roughness of the ice canopy was not considered. The BELLHOP model was introduced to calculate the transmission loss in shallow water under ice canopy and the performance of a vertical array was analyzed [7], but the inhomogeneity of the ice canopy was not contemplated. The phenomenon of overlapping sound lines [8] occurs if the sound signals propagate over a long distance under ice, and the communication can be realized by applying adaptive coherent communication technology. The transmission loss of shallow source is very large because of the scattering of the ice-water mixed layer [9] and the signal can hardly be propagated for a long distance. The long-range propagation needs certain conditions [10], such as the source should be located at a specific depth; however, the constraint effect of sound velocity gradient in ice-water mixed layer was not taken into account. The ice layer was considered as a homogeneous medium without microstructure in above researches, and the authors only focused on the macroscopic equivalent parameters of the ice layer, other than 


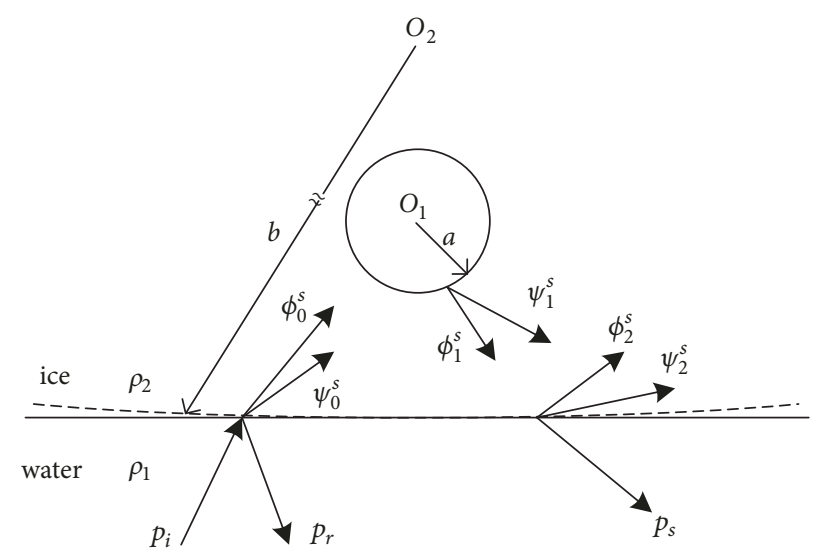

FIGURE 1: Schematic diagram of scattering model.

the influence of microstructure in ice on the macroscopic characteristics.

The scattering by microstructures in ice is an elastic scattering problem. The scattering of elastic waves is accompanied by the conversion of particle polarization modes and energy redistribution of longitudinal waves and transverse waves. Therefore, the physical characteristics and mathematical methods of the elastic scattering problem are more complicated than those in fluids [11]. Many methods were introduced to solve the problem [12], among which the Fourier-Bessel series [13] approximating the plane half-space surface as a circular surface of large radius is an effective method. However, it is generally used to solve half-space problems $[14,15]$, such as the scattering of seismic waves near the earth's surface[16], and it has poor convergence for the scattering problem in two contiguous half-spaces. The Sommerfeld-Watson transformation $[17,18]$ is a more efficient solution to the scattering problem of a regular cylindrical obstacle, but it cannot be directly applied to the scattering problem of a plane interface [19]. In engineering applications, the calculation error can be controlled within an acceptable range by selecting reasonable parameters [20]. The combination of Fourier-Bessel series and SommerfeldWatson transformation gives full play to the advantages of two methods, which can not only realize the fast convergence of the underwater acoustic field but also retain the main characteristics of the spatial distribution of acoustic energy. The influence of a slender cylindrical cavity near and parallel to the ice-water interface on the acoustic propagation under ice is analyzed using the combination of Fourier-Bessel series and Sommerfeld-Watson transformation.

\section{Solutions}

The ice and water media can be considered as in two contiguous half-spaces if the ice thickness and water depth are much larger than the wave train length of a short pulse source; the problem is simplified into a two-dimensional model as shown in Figure 1.

A plane wave $p_{i}$ in water is incident on the ice-water interface and generate reflected wave $p_{r}$ and transmitted waves $\phi_{i}$ and $\psi_{i}$. The acoustic field in ice and water will be distorted due to the cavity as shown in Figure 1. Assume that scattering of the cavity is $\phi_{1}^{s}$ and $\psi_{1}^{s}$, scattering of the ice-water interface in ice is $\phi_{2}^{s}$ and $\psi_{2}^{s}$, and scattering of the ice-water interface in water is $p_{s}$.

A convex approximation of the ice-water interface is introduced because it is very complicated to deal with the horizontal interface using cylindrical functions. The radius of the cavity is $a$, and the radius of the ice-water interface is $b$. A minor error will be introduced to the calculation by the geometric deviation if $b \gg a$. Two cylindrical coordinate systems $r_{1}-\varphi_{1}$ and $r_{2}-\varphi_{2}$ are established, respectively, with the centers of the cavity and ice-water interface. The displacement potential in ice is set as follows:

$$
\begin{aligned}
& \phi_{0}^{s}=\sum_{n=0}^{\infty} J_{n}\left(k_{L} r_{\varepsilon}\right)\left(\mathrm{A}_{\varepsilon n}^{\mathrm{e} 0} \cos n \varphi_{\varepsilon}+\mathrm{A}_{\varepsilon n}^{\mathrm{o} 0} \sin n \varphi_{\varepsilon}\right) \\
& \psi_{0}^{s}=\sum_{n=0}^{\infty} J_{n}\left(k_{T} r_{\varepsilon}\right)\left(\mathrm{B}_{\varepsilon n}^{\mathrm{o} 0} \sin n \varphi_{\varepsilon}+\mathrm{B}_{\varepsilon n}^{\mathrm{e} 0} \cos n \varphi_{\varepsilon}\right) \\
& \phi_{1}^{s}=\sum_{n=0}^{\infty} H_{n}^{(1)}\left(k_{L} r_{\varepsilon}\right)\left(\mathrm{A}_{\varepsilon n}^{\mathrm{e} 1} \cos n \varphi_{\varepsilon}+\mathrm{A}_{\varepsilon n}^{\mathrm{o} 1} \sin n \varphi_{\varepsilon}\right) \\
& \psi_{1}^{s}=\sum_{n=0}^{\infty} H_{n}^{(1)}\left(k_{T} r_{\varepsilon}\right)\left(\mathrm{B}_{\varepsilon n}^{\mathrm{o} 1} \sin n \varphi_{\varepsilon}+\mathrm{B}_{\varepsilon n}^{\mathrm{e} 1} \cos n \varphi_{\varepsilon}\right) \\
& \phi_{2}^{s}=\sum_{n=0}^{\infty} J_{n}\left(k_{L} r_{\varepsilon}\right)\left(\mathrm{A}_{\varepsilon n}^{\mathrm{e} 2} \cos n \varphi_{\varepsilon}+\mathrm{A}_{\varepsilon n}^{\mathrm{o} 2} \sin n \varphi_{\varepsilon}\right) \\
& \psi_{2}^{s}=\sum_{n=0}^{\infty} J_{n}\left(k_{T} r_{\varepsilon}\right)\left(\mathrm{B}_{\varepsilon n}^{\mathrm{o} 2} \sin n \varphi_{\varepsilon}+\mathrm{B}_{\varepsilon n}^{\mathrm{e} 2} \cos n \varphi_{\varepsilon}\right)
\end{aligned}
$$

The coefficients in the scalar or vector potential functions are represented, respectively, by $\mathrm{A}$ or $\mathrm{B}$, and $\mathrm{A}_{\varepsilon n}^{\mathrm{e} 0}, \mathrm{~A}_{\varepsilon n}^{\mathrm{o} 0}, \mathrm{~B}_{\varepsilon n}^{\mathrm{o} 0}$, and $\mathrm{B}_{\varepsilon n}^{\mathrm{e} 0}$ are the known coefficients of transmitted waves $[14,15]$; $\varepsilon=1,2$ in subscripts represents $r_{1}-\varphi_{1}$ or $r_{2}-\varphi_{2}$ coordinate system, $n$ in superscripts is the integral orders of cylindrical function, o or e in superscripts corresponds to the parity of trigonometric function, $k_{L}$ is the longitudinal wave number, and $k_{T}$ is the transverse wave number. 


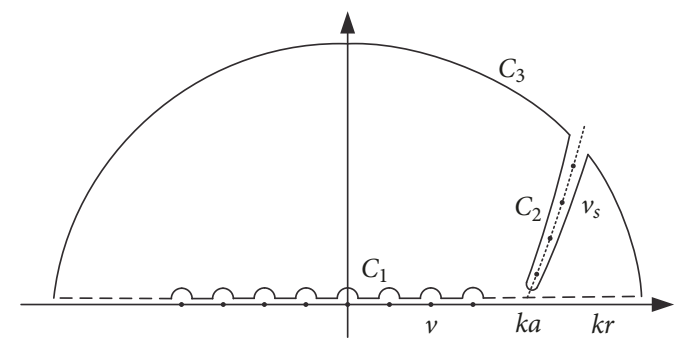

FIGURE 2: Schematic diagram of integration path in complex plane.

Acoustic field in fluid is usually expressed by sound pressure. Therefore, the expression of the scattering field in water is set as follows:

$$
\begin{aligned}
p_{s} & =\sum_{n=0}^{\infty} R_{n}(r) \Phi_{n}(\varphi) \\
& =\sum_{n=0}^{\infty} Z_{n}^{(l)}\left(k_{1} r_{\varepsilon}\right)\left(\mathrm{A}_{\varepsilon n}^{\mathrm{e} 3} \cos n \varphi_{\varepsilon}+\mathrm{A}_{\varepsilon n}^{\mathrm{o} 3} \sin n \varphi_{\varepsilon}\right)
\end{aligned}
$$

where $k_{1}$ represents the wave number in water. The Sommerfeld-Watson transformation is appropriate to reform the acoustic field into a new complex-order series solution to achieve fast convergence. The transformation is carried out on (2):

$$
p_{s}=\frac{i}{2} \int_{C_{1}} \frac{R_{v}(r) e^{i v(\varphi-\pi)}}{\sin \pi v} \mathrm{~d} v
$$

As shown in Figure $2,1 / \sin \pi v$ in the integrand is a singular function when $v$ is an integer, while $R_{v}(r)$ is a singular function when $v=v_{s}$ is a complex, where $v_{s}$ is a singular point in complex plane and $C_{2}$ is an integral path that bypasses the secant including all the complex singular points $v_{s}$.

It can be proved that $p_{s}$ equals the sum of residues at all the singular complex points $v_{s}$ in complex plane. The complex $v_{s}$ causes exponential decay of the acoustic field propagating along the circumferential direction. Therefore, SommerfeldWatson transformation can realize fast convergence for the problem in this paper. The displacement continuity equation shown in appendix (A.3) is substituted into (3) and a steepest descent equation is obtained:

$$
\varphi \pm \cos ^{-1} \frac{v}{k_{L, T} b}-\cos ^{-1} \frac{v}{k_{1} r}+\cos ^{-1} \frac{v}{k_{1} b}=0
$$

A graphic method is used to solve the transcendental equation in (4), as shown in Figure 3.

$\varphi$ is the observation direction and $\gamma$ is the reflection of direct wave on the ice-water interface. Then SommerfeldWatson transformation is carried out on the stress continuous equation shown in appendix (A.1) and (A.2) and another steepest descent equation is obtained:

$$
\cos ^{-1} \frac{n \pm v}{k_{L} D} \pm \cos ^{-1} \frac{v}{k_{L} b}-\cos ^{-1} \frac{v}{k_{T} b}=0
$$

In the same way, a graphic method is used to solve the transcendental equation of formula (5), as shown in Figure 4.

As can be seen that $n$ and $v$ coexist in Figure 4; that is, the scattering of the cavity in ice is still expressed by the classical integer series with the order $n$, and the scattering of the ice-water interface is jointly represented by the steady phase integral at the point $v$ and the complex series order $v_{s}$. The acoustic field under ice is obtained by solving the above simultaneous equations.

\section{Numerical Analysis}

The medium and geometric parameters are shown in Table 1 . The incident angle $\varphi_{i}$ is defined as the included angle between the incident direction of $p_{i}$ and the normal vector of ice-water interface, $\varphi_{s}$ is the scattering angle, and $\varphi_{s}=-\varphi_{i}$ is the mirror reflection direction.

The sound pressure level of underwater scattering field vs. $\varphi_{i}$ and $\varphi_{s}$ for $h / a=1.2$ and $f=200 \mathrm{kHz}$ is shown in Figure 5.

As can be seen from Figure 5, the scattering field presents a fast fluctuating interference pattern due to the joint action of the cavity and ice-water interface if $\varphi_{i}<\varphi_{T}$ and $\left|\varphi_{s}\right|<$ $\varphi_{T}$. The acoustic energy in the direction of mirror reflection is much higher than that in other scattering angles, and the reflected wave presents a beam at supercritical incidence. The reflection coefficient of the ice-water interface with a cavity in this paper is marked by $R$, and the reflection coefficient without a cavity is marked by $R_{0}$.

The long-range propagation modes in an acoustic channel under ice are basically caused by supercritical incidence, and the scattering of a near-interface cavity in ice changes the spatial distribution of the acoustic energy under ice and thereby affects the transmission loss. Therefore, this paper focuses on the acoustic characteristics of reflection coefficient at supercritical incidence.

3.1. Angular Characteristics of $R$. The amplitude of inhomogeneous plane wave in ice attenuates with depth at supercritical incidence, and the acoustic energy returns to water after propagating for a distance along the horizontal direction. Therefore, the shallow surface on the cavity plays a major role in the scattering field, and a variable cross-section waveguide is formed by a section of the shallow surface on the cavity and the ice-water interface, as shown in Figure 6.

During the propagation of the inhomogeneous plane wave in the variable cross-section waveguide for a certain distance, the horizontal wave number changes when the 
TABLE 1: Media parameters and geometric dimensions.

\begin{tabular}{lcc}
\hline Variable & Value & Description/Explanation \\
\hline$\rho_{1}$ & $1000 \mathrm{~kg} / \mathrm{m}^{3}$ & density of water \\
$\rho_{2}$ & $917 \mathrm{~kg} / \mathrm{m}^{3}$ & density of ice \\
$c_{1}$ & $1480 \mathrm{~m} / \mathrm{s}$ & longitudinal wave velocity in water \\
$c_{L}$ & $3647 \mathrm{~m} / \mathrm{s}$ & longitudinal wave velocity in ice \\
$c_{T}$ & $1729 \mathrm{~m} / \mathrm{s}$ & transverse wave velocity in ice \\
$\varphi_{L}$ & $23.94 \mathrm{deg}$ & critical angle of longitudinal wave in ice \\
$\varphi_{T}$ & $58.87 \mathrm{deg}$ & critical angle of transverse wave in ice \\
$a$ & $0.05 \mathrm{~m}$ & cavity radius \\
$h$ & $0.06-0.15 \mathrm{~m}$ & vertical distance between the cavity and ice-water interface \\
$f$ & $20-200 \mathrm{kHz}$ & incident frequency \\
$k$ & $83.8-837.8 \mathrm{rad} / \mathrm{m}$ & wavenumber \\
$k a$ & $4.2-41.9$ & Helmholtz number \\
$h / a$ & $1.2-3.0$ & relative depth \\
\hline
\end{tabular}

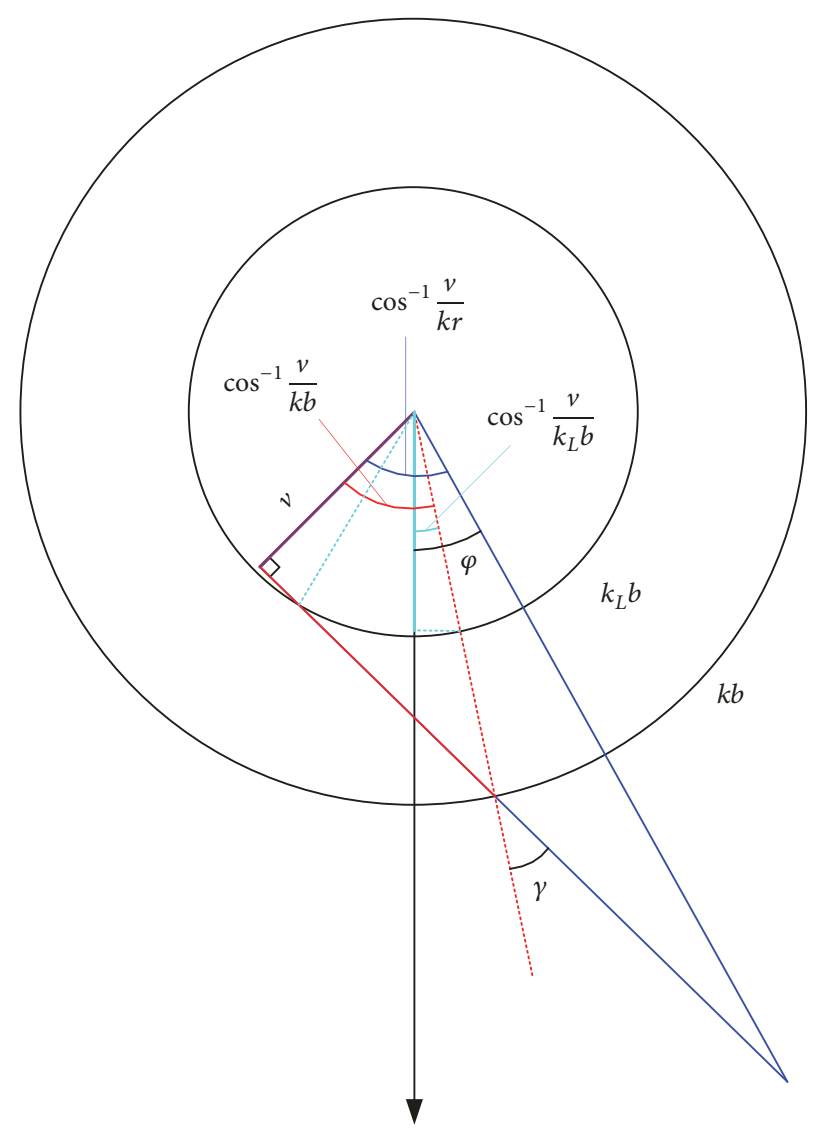

FIGURE 3: The graphical method for steepest descent equation in (4).

inhomogeneous plane wave returns to water, which causes a deflection of the reflection direction.

It is very difficult to find an analytical solution of the acoustic field in the variable cross-section waveguide, so some reasonable approximations are introduced: (1) The longitudinal component of the inhomogeneous plane wave attenuates much more with depth, so only the contribution of transverse component in the inhomogeneous plane wave is considered, and the mode conversion of elastic wave on the waveguide interface is ignored; (2) the upper boundary of the variable cross-section waveguide is approximated to a horizontal step shape, assuming that the acoustic field in the waveguide can be expressed by the following form with introducing a minor error:

$$
\psi=\sum_{n} \exp \left\{i k_{x}(n, x) x\right\} \cos \left\{k_{z}(n, x) z\right\}
$$




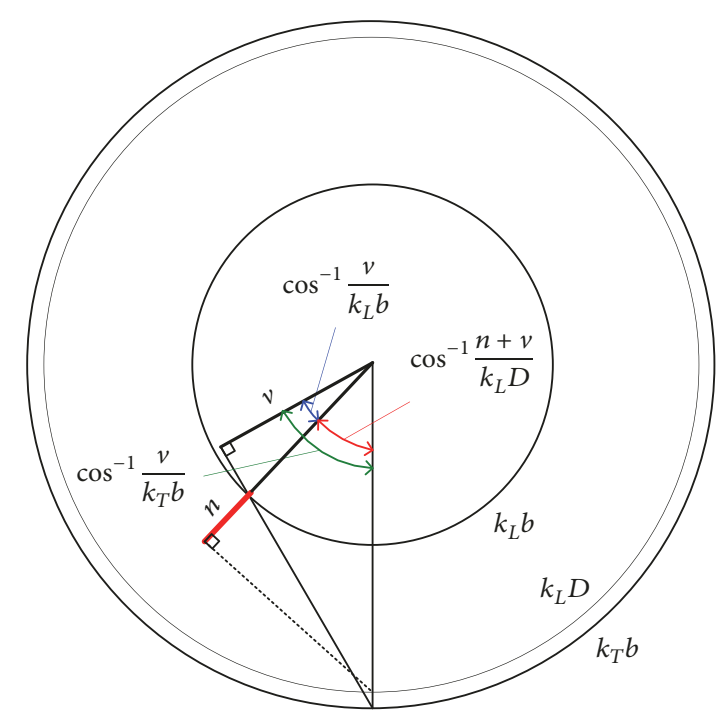

FIGURE 4: The graphical method for steepest descent equation in (5).

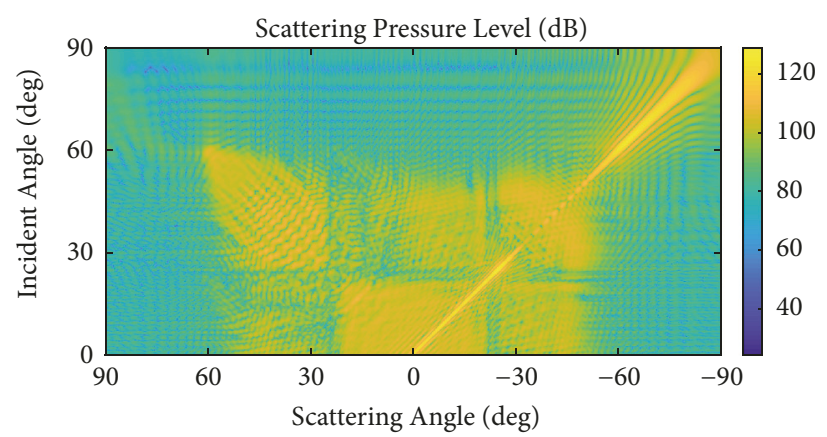

FIgURE 5: The scattering field under ice.

The incident angle at supercritical incidence is very large on ice-water interface and the beam-width is small. It can be approximately considered as that $\cos \varphi \approx \cos \varphi_{i}$, so the beamwidth $\Delta \varphi$ is equal to

$$
\Delta \varphi \approx \sec \varphi_{i} \frac{\Delta k_{x}}{k}
$$

The beam-width $\Delta \varphi$ depends on the incident angle $\varphi_{i}$ and the horizontal wave number variation $\Delta k_{x}$, which is not significant compared with $\sec \varphi_{i}$ if the geometry parameters and incident frequency are constants. The relation between beam-width and incident angle is shown in Figure 7.

As can be seen from Figure 7, the relationship between the beam-width and the incident angle predicted by (7) is consistent with the trend of numerical results. There are some differences between the theoretical prediction and the numerical results because the incident angle and the scattering angle are discrete values.

Assume that the effective horizontal area of the variable cross-section waveguide to deflect the reflection is $S$ and the sound pressure in the beam is approximately sinusoidal and its peak appears in the mirror reflection direction. It can be known from the conservation of energy that

$$
I_{i} \cdot S \cdot \cos \varphi_{i}=2 \int_{0}^{\Delta \varphi_{r}} I_{r}(\varphi) \mathrm{d} \varphi \approx I_{r} \Delta \varphi
$$

where $I$ is sound intensity and $I_{i}=p_{i}^{2} /\left(\rho_{1} c_{1}\right), I_{r} \approx$ $p_{r}^{2} /\left(\rho_{1} c_{1}\right)$ in far-field. The wave impedance of the reflected wave equals the characteristic impedance of the medium if the wave propagates to a sufficient distance in the mirror reflection direction, and the expression of reflection coefficient $R$ can be written as follows:

$$
R \approx \cos \varphi_{i} \sqrt{\frac{S}{\Delta k_{x} / k}}
$$

It is found that the effective horizontal area and horizontal wave velocity variation are not significant compared with $\cos \varphi_{i}$, and the reflection coefficient $R$ is approximately proportional to the cosine of incident angle, as shown in Figure 8.

As can be seen from Figure 8, the reflection coefficients $R$ and $R_{0}$ are obviously different; especially $R$ is less than 1 at supercritical incidence, and it decreases with the increase of the incident angle. The predicted trend of $R$ at supercritical incidence according to (9) is in good agreement with the actual result, which is consistent with the phenomenon 


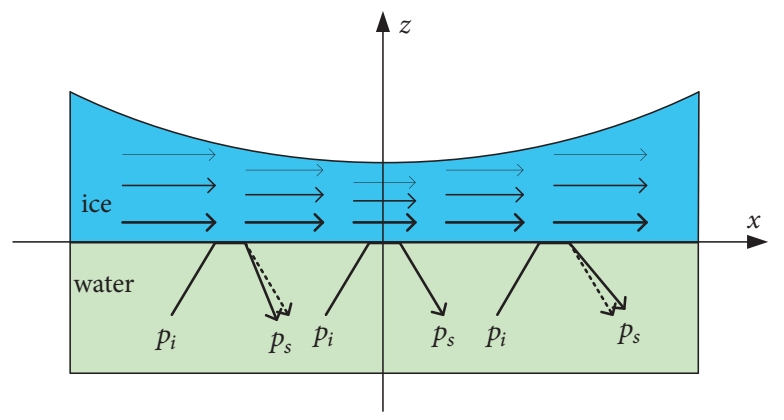

FIGURE 6: Schematic diagram of the variable cross-section waveguide.

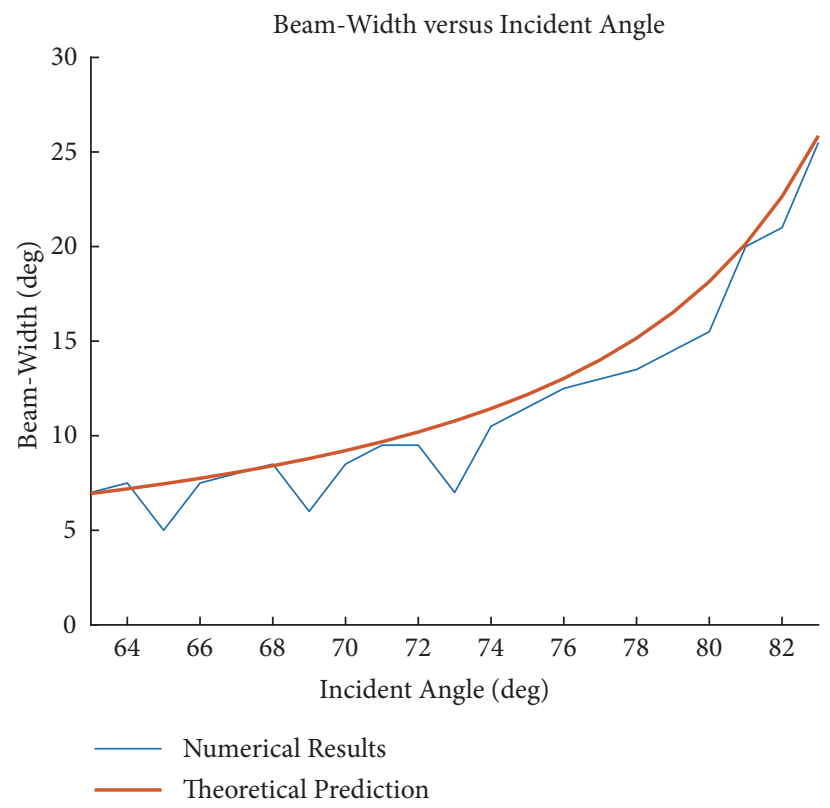

FIgURE 7: Beam-width vs. incident angle.

that the beam-width increases with the incidence angle at supercritical angle, as shown in Figure 5.

In summary, the effective horizontal area and horizontal wave velocity variation is not significant compared with the incident angle if the geometry parameters and incident frequency are constants, and the beam-width is proportional to secant of incident angle, while the reflection coefficient is proportional to cosine of incident angle.

3.2. Frequency Characteristics of $R$. In practical application, the equipment and operations required to measure the beamwidth are very complicated, while it is easier to measure the frequency characteristic of reflection coefficient at a fixed incident angle.

The radical formula in (9) is defined as $R^{\prime}=R / \cos \varphi_{i}$, which characterizes the influence of geometry parameters and incident frequency in the reflection coefficient $R$ and its relation with the relative depth $h / a$ and Helmholtz number $k a$ is shown in Figure 9.

As can be seen from Figure 9, $R^{\prime}$ and incident angle are hardly irrelevant, and $R^{\prime}$ increases with Helmholtz number. The variation of horizontal wave number is approximated to the first term of its Taylor series, deriving $\Delta k_{x} \approx$ $k_{x}^{\prime}(x) \Delta x$, where $k_{x}^{\prime}(x)$ is the spatial derivative of horizontal wave number $k_{x}(x)$ to horizontal location $x$ and $\Delta x$ is the horizontal migration length of inhomogeneous plane wave in the variable cross-section waveguide. The maximum of $\Delta \varphi$ depends on $k_{x}^{\prime \prime}(x)=0$, and an implicit function in appendix (A.8) is determined. Its approximate explicit function has the expression $z(\omega) \approx g_{1}(h, a) \cdot \omega^{-1}$ because of $\omega \gg z(\omega)$. It could be proved that $k_{x}^{\prime}(x) \propto \omega, \Delta \varphi \propto \omega^{-1}$, and dimensions are measured in terms of the wavelength in acoustics, so the expression of reflection coefficient $R$ is expressed in the dimensionless Helmholtz number and relative depth:

$$
R\left(\frac{h}{a}, k a, \varphi_{i}\right)=f\left(\frac{h}{a}\right) \sqrt{k a} \cos \varphi_{i}
$$

where

$$
f\left(\frac{h}{a}\right)=\frac{0.03547 h}{a}+0.04022
$$

The numerical results and theoretical predictions of $R^{\prime}$ are shown in Figure 10. The numerical results are marked with 


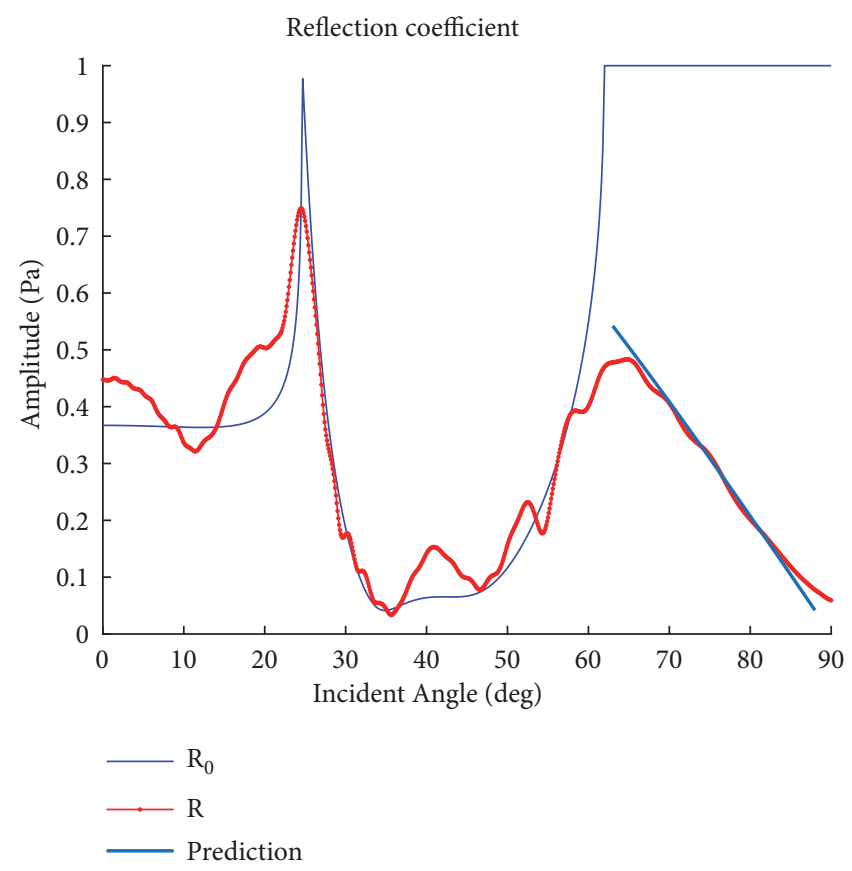

Figure 8: Reflection coefficients $R_{0}, R$ and theoretical prediction.

different line-types, and the solid lines with corresponding colors are the theoretical predictions.

As can be seen from Figure 10, the theoretical predictions are in very good agreement with the numerical results. $R^{\prime}$ increases with the relative depth $h / a$; that is, the deflection effect of the variable cross-section waveguide and the beamwidth of reflected wave become smaller if the ice cavity is away from the ice-water interface, and the reflection coefficient correspondingly becomes greater. This feature can also be seen through the formula (10) and (11), which means the scattering of the ice cavity becomes weaker with the increasing relative depth and incident frequency.

\section{Conclusions}

In this paper, the Fourier-Bessel series and SommerfeldWatson transformation method are used to analyze the influence of a slender cylindrical cavity near and parallel to an ice-water interface on the sound propagation in an acoustic channel under ice. Through research, it is found that, due to the joint action of the cavity and the ice-water interface, the underwater acoustic field presents a fast fluctuating interference pattern, and what is more, the acoustic field in the mirror reflection direction has the following characteristics at supercritical incidence:

(a) The beam-width is proportional to secant of incident angle.

(b) The reflection coefficient is proportional to cosine of incident angle.

(c) The reflection coefficient increases with Helmholtz number and relative depth if incident angle is a constant.

The scattering of the inhomogeneous plane wave in ice by a cavity changes the spatial distribution of underwater acoustic energy, making the transmission loss during long-distance communication much larger than that of the ice-water interface without a cavity. The research provides a theoretical basis for an in-depth understanding of the acoustic channel under ice, as well as supporting the detection and identification of underwater targets and communication technology under ice.

\section{Appendix}

(1) Boundary Continuous Equation (Matrix Form). Normal stress continuity equation:

$$
\begin{aligned}
& {\left[E^{(3)}(a, n)\right]\left(\begin{array}{l}
\mathrm{A}_{1 n}^{\mathrm{e} 1} \\
\mathrm{~B}_{1 n}^{\mathrm{o} 1}
\end{array}\right)+\left[E^{(1)}(a, n)\right]\left(\begin{array}{l}
\mathrm{A}_{1 n}^{\mathrm{e} 0}+\mathrm{A}_{1 n}^{\mathrm{e} 2} \\
\mathrm{~B}_{1 n}^{\mathrm{o} 0}+\mathrm{B}_{1 n}^{\mathrm{o} 2}
\end{array}\right)} \\
& =\left(\begin{array}{l}
0 \\
0
\end{array}\right) \\
& {\left[E^{(3)}(b, n)\right]\left(\begin{array}{c}
\mathrm{A}_{2 n}^{\mathrm{e} 1} \\
\mathrm{~B}_{2 n}^{\mathrm{o} 1}
\end{array}\right)+\left[E^{(1)}(b, n)\right]\left(\begin{array}{l}
\mathrm{A}_{2 n}^{\mathrm{e} 2} \\
\mathrm{~B}_{2 n}^{\mathrm{o} 2}
\end{array}\right)} \\
& =-\frac{b^{2}}{2 \mu}\left(\begin{array}{c}
\mathrm{A}_{2 n}^{\mathrm{e} 3} \\
0
\end{array}\right)
\end{aligned}
$$

Tangential stress continuity equation:

$$
\begin{aligned}
& {\left[E_{-}^{(3)}(a, n)\right]\left(\begin{array}{c}
\mathrm{A}_{1 n}^{\mathrm{o} 1} \\
\mathrm{~B}_{1 n}^{\mathrm{e} 1}
\end{array}\right)+\left[E_{-}^{(1)}(a, n)\right]\left(\begin{array}{c}
\mathrm{A}_{1 n}^{\mathrm{o} 0}+\mathrm{A}_{1 n}^{\mathrm{o} 2} \\
\mathrm{~B}_{1 n}^{\mathrm{e} 0}+\mathrm{B}_{1 n}^{\mathrm{e} 2}
\end{array}\right)} \\
& \quad=\left(\begin{array}{l}
0 \\
0
\end{array}\right)
\end{aligned}
$$


$\mathrm{R}^{\prime}$ vs. ka and incident angle $(\mathrm{h} / \mathrm{a}=1.2)$

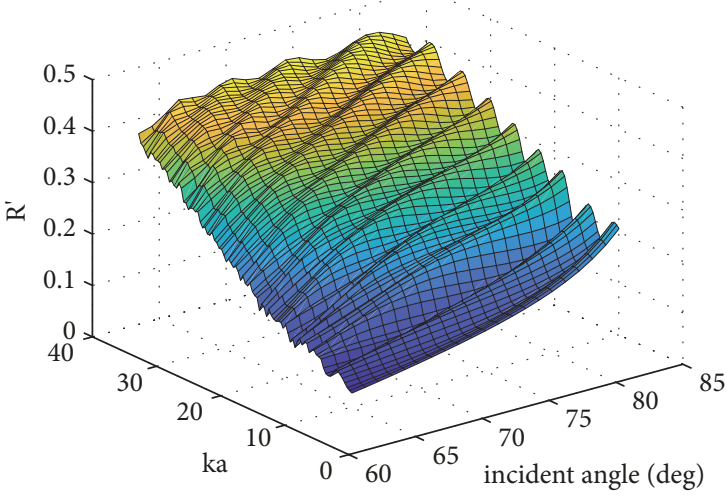

(a) $h / a=1.2$

$\mathrm{R}^{\prime}$ vs. ka and incident angle $(\mathrm{h} / \mathrm{a}=2.0)$

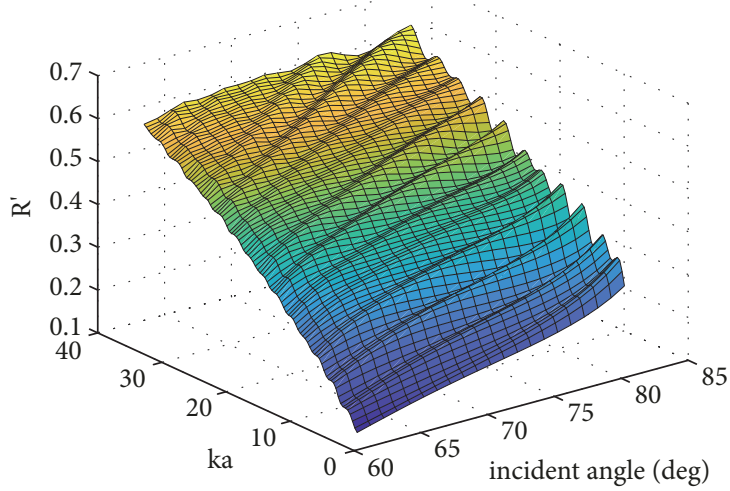

(c) $h / a=2.0$
$\mathrm{R}^{\prime}$ vs. ka and incident angle $(\mathrm{h} / \mathrm{a}=1.6)$

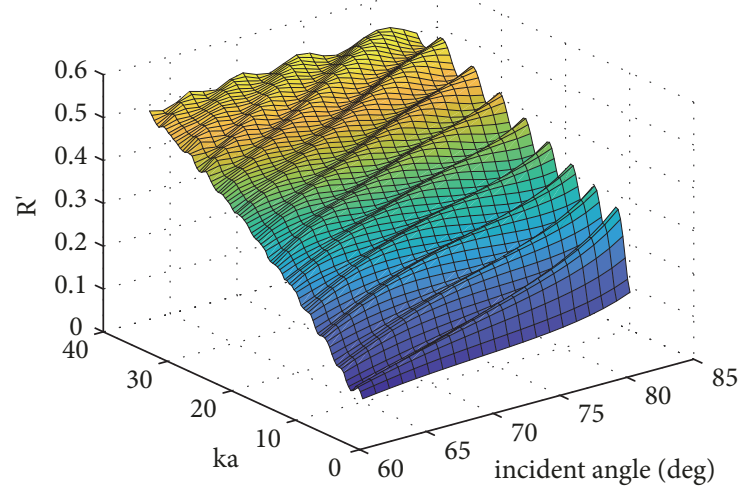

(b) $h / a=1.6$

$\mathrm{R}^{\prime}$ vs. ka and incident angle $(\mathrm{h} / \mathrm{a}=2.5)$

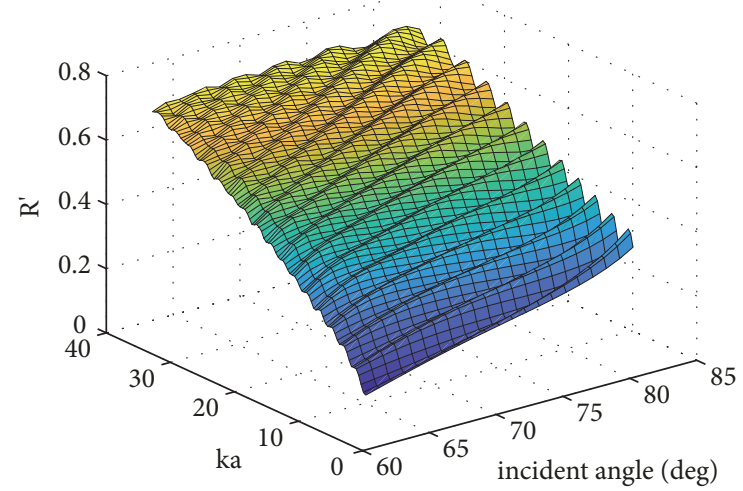

(d) $h / a=2.5$

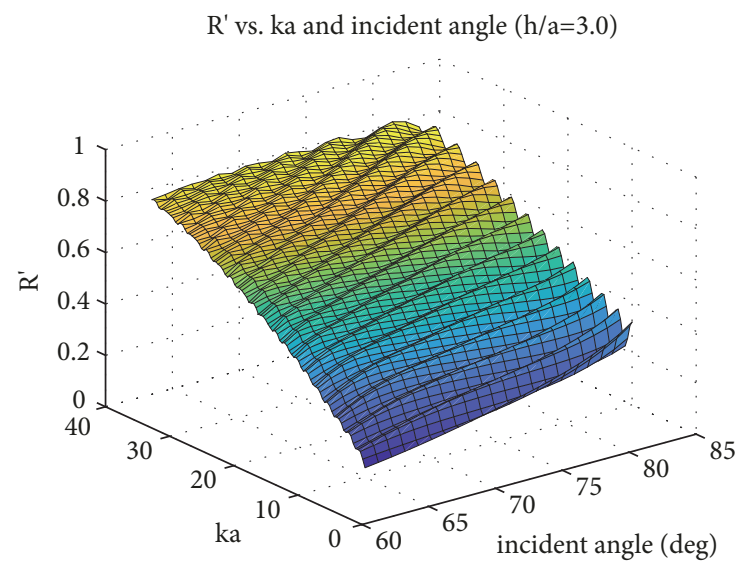

(e) $h / a=3.0$

FIGURE 9: $R^{\prime}$ vs. ka and incident angle.

$$
\begin{aligned}
& {\left[E_{-}^{(3)}(b, n)\right]\left(\begin{array}{c}
\mathrm{A}_{2 n}^{\mathrm{o} 1} \\
\mathrm{~B}_{2 n}^{\mathrm{e} 1}
\end{array}\right)+\left[E_{-}^{(1)}(b, n)\right]\left(\begin{array}{c}
\mathrm{A}_{2 n}^{\mathrm{o} 2} \\
\mathrm{~B}_{2 n}^{\mathrm{e} 2}
\end{array}\right)} \\
& =-\frac{b^{2}}{2 \mu}\left(\begin{array}{c}
\mathrm{A}_{2 n}^{\mathrm{o} 3} \\
0
\end{array}\right)
\end{aligned}
$$

Normal displacement continuous equation:

$$
\begin{aligned}
& {\left[F^{(3)}(b, n)\right]\left(\begin{array}{l}
\mathrm{A}_{2 n}^{\mathrm{e} 1} \\
\mathrm{~B}_{2 n}^{\mathrm{o} 1}
\end{array}\right)+\left[F^{(1)}(b, n)\right]\left(\begin{array}{l}
\mathrm{A}_{2 n}^{\mathrm{e} 2} \\
\mathrm{~B}_{2 n}^{\mathrm{o} 2}
\end{array}\right)=\frac{\mathrm{A}_{2 n}^{\mathrm{e} 3}}{\rho_{1} \omega^{2}}} \\
& {\left[F^{(3)}(b, n)\right]\left(\begin{array}{l}
\mathrm{A}_{2 n}^{\mathrm{o} 1} \\
\mathrm{~B}_{2 n}^{\mathrm{e} 1}
\end{array}\right)+\left[F^{(1)}(b, n)\right]\left(\begin{array}{l}
\mathrm{A}_{2 n}^{\mathrm{o} 2} \\
\mathrm{~B}_{2 n}^{\mathrm{e} 2}
\end{array}\right)=\frac{\mathrm{A}_{2 n}^{\mathrm{o} 3}}{\rho_{1} \omega^{2}}}
\end{aligned}
$$




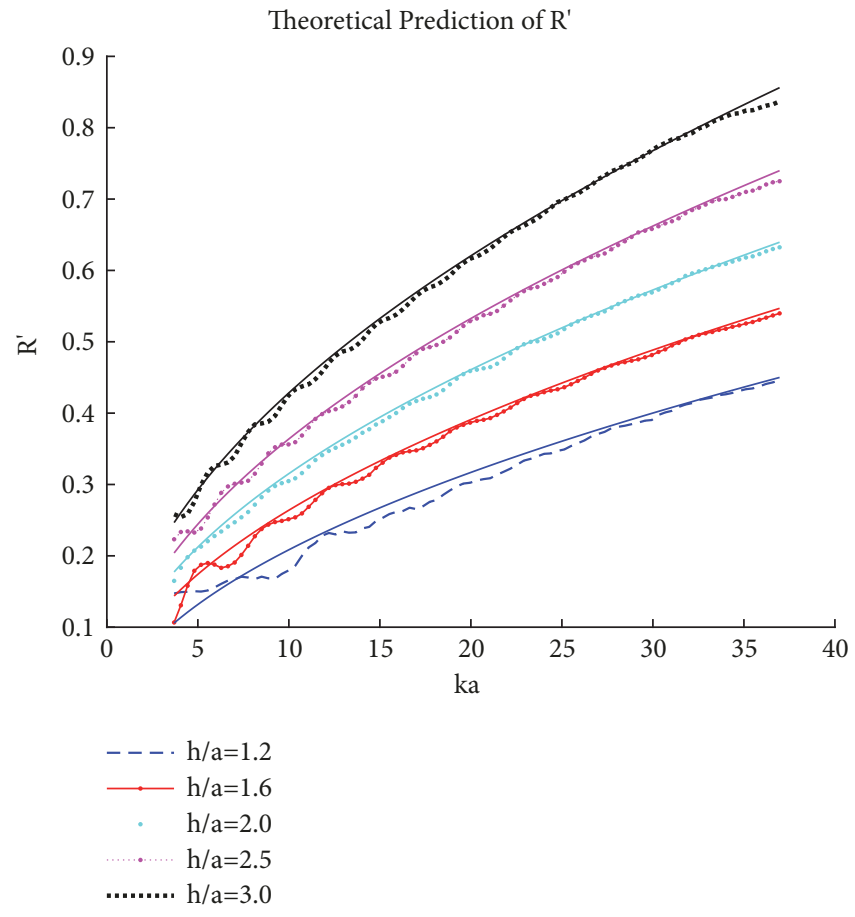

FIgURE 10: Theoretical prediction of $R^{\prime}$.

wherein $\rho_{1}$ is the density of water and $\mu$ is the second parameter of the Lamé constant of ice. The matrix element expression is as follows:

$$
\begin{aligned}
& {\left[E^{(l)}(r, n)\right]=\left[\begin{array}{ll}
E_{11}^{(l)}(r, n) & E_{12}^{(l)}(r, n) \\
E_{21}^{(l)}(r, n) & E_{22}^{(l)}(r, n)
\end{array}\right],} \\
& {\left[E_{-}^{(l)}(r, n)\right]=\left[\begin{array}{cc}
E_{11}^{(l)}(r, n) & -E_{12}^{(l)}(r, n) \\
-E_{21}^{(l)}(r, n) & E_{22}^{(l)}(r, n)
\end{array}\right]}
\end{aligned}
$$

wherein

$$
\begin{aligned}
& E_{11}^{(l)}= {\left[n^{2}+n-\frac{1}{2}\left(k_{T} r\right)^{2}\right] Z_{n}^{(l)}\left(k_{L} r\right) } \\
&-k_{L} r Z_{n-1}^{(l)}\left(k_{L} r\right) \\
& E_{12}^{(l)}=n {\left[k_{T} r Z_{n-1}^{(l)}\left(k_{T} r\right)-(n+1) Z_{n}^{(l)}\left(k_{T} r\right)\right] } \\
& E_{21}^{(l)}=n\left[(n+1) Z_{n}^{(l)}\left(k_{L} r\right)-k_{L} r Z_{n-1}^{(l)}\left(k_{L} r\right)\right] \\
& E_{22}^{(l)}=k_{T} r Z_{n-1}^{(l)}\left(k_{T}^{r} r\right) \\
&-\left[n^{2}+n-\frac{1}{2}\left(k_{T} r\right)^{2}\right] Z_{n}^{(l)}\left(k_{T} r\right)
\end{aligned}
$$

and

$$
\begin{aligned}
& {\left[F^{(l)}(r, n)\right]=\left[\begin{array}{ll}
F_{1}^{(l)}(r, n) & F_{2}^{(l)}(r, n)
\end{array}\right],} \\
& {\left[F_{-}^{(l)}(r, n)\right]=\left[\begin{array}{ll}
F_{1}^{(l)}(r, n) & -F_{2}^{(l)}(r, n)
\end{array}\right]}
\end{aligned}
$$

wherein

$$
\begin{aligned}
& F_{1}^{(l)}(r, n)=\frac{Z_{n}^{(l)}\left(k_{L} r\right)}{H_{n}^{\prime(1)}\left(k_{1} b\right)} \\
& F_{2}^{(l)}(r, n)=\frac{(n / b) H_{n}^{(1)}\left(k_{T} r\right)}{H_{n}^{\prime(1)}\left(k_{1} b\right)}
\end{aligned}
$$

(2) Sommerfeld-Watson Transformation for the Scattering Field under Ice:

$$
p_{s}=I_{1}^{s}+I_{2}^{s}+I_{3}^{s}+I_{4}^{s}
$$

wherein

$$
\begin{aligned}
I_{1}^{s}= & \frac{i}{2} \int_{c}\left(\mathrm{~A}_{2 v}^{\mathrm{e} 1}-i \mathrm{~A}_{2 v}^{\mathrm{o} 1}\right) \frac{H_{v}^{\prime(1)}\left(k_{L} b\right)}{H_{v}^{(1)}\left(k_{1} b\right)} H_{v}^{(1)}\left(k_{1} r_{2}\right) \\
& \cdot \frac{e^{i v(\varphi-\pi)}}{\sin v \pi} \mathrm{d} v \\
I_{2}^{s}= & \frac{i}{2} \int_{c}\left(\mathrm{~B}_{2 v}^{\mathrm{o} 1}-i \mathrm{~B}_{2 v}^{\mathrm{e} 1}\right) \frac{v}{b} \frac{H_{v}^{(1)}\left(k_{T} b\right)}{H_{v}^{\prime(1)}\left(k_{1} b\right)} H_{v}^{(1)}\left(k_{1} r_{2}\right) \\
& \cdot \frac{e^{i v(\varphi-\pi)}}{\sin v \pi} \mathrm{d} v \\
I_{3}^{s}= & \frac{i}{2} \int_{c}\left(\mathrm{~A}_{2 v}^{\mathrm{e} 2}-i \mathrm{~A}_{2 v}^{\mathrm{o} 2}\right) \\
& \cdot \frac{H_{v}^{\prime(1)}\left(k_{L} b\right)+H_{v}^{\prime(2)}\left(k_{L} b\right)}{2 H_{v}^{\prime(1)}\left(k_{1} b\right)} H_{v}^{(1)}\left(k_{1} r_{2}\right) \frac{e^{i v(\varphi-\pi)}}{\sin v \pi} \mathrm{d} v
\end{aligned}
$$




$$
\begin{aligned}
I_{4}^{s} & =\frac{i}{2} \int_{c}\left(\mathrm{~B}_{2 v}^{\mathrm{o} 2}-i \mathrm{~B}_{2 v}^{\mathrm{e} 2}\right) \\
& \cdot \frac{v}{b} \frac{H_{v}^{(1)}\left(k_{T} b\right)+H_{v}^{(2)}\left(k_{T} b\right)}{2 H_{v}^{\prime(1)}\left(k_{1} b\right)} H_{v}^{(1)}\left(k_{1} r_{2}\right) \frac{e^{i v(\varphi-\pi)}}{\sin v \pi} \mathrm{d} v
\end{aligned}
$$

(3) Sommerfeld-Watson Transformation for Boundary Continuity Equations:

$$
\begin{aligned}
& \mathrm{A}_{1 n}^{\mathrm{e} 1}=I_{1}^{a}+I_{2}^{a}+I_{3}^{a} \\
& \mathrm{~A}_{1 n}^{\mathrm{o} 1}=I_{1}^{b}+I_{2}^{b}+I_{3}^{b} \\
& \mathrm{~B}_{1 n}^{\mathrm{o} 1}=I_{1}^{c}+I_{2}^{c}+I_{3}^{c} \\
& \mathrm{~B}_{1 n}^{\mathrm{e} 1}=I_{1}^{d}+I_{2}^{d}+I_{3}^{d}
\end{aligned}
$$

wherein

$$
\begin{aligned}
& I_{1}^{a}=i \int_{c} \mathrm{~B}_{2 v}^{o 1} \\
& \cdot \frac{J_{n+v}\left(k_{L} D\right)+(-)^{n} J_{n-v}\left(k_{L} D\right)}{H_{v}^{(1)}\left(k_{L} b\right) \sin v \pi} H_{v}^{(1)}\left(k_{T} b\right) \mathrm{d} v \\
& I_{2}^{a}=i \int_{c} \mathrm{~A}_{2 v}^{\mathrm{e} 2} \\
& \cdot \frac{J_{n+v}\left(k_{L} D\right)+(-)^{n} J_{n-v}\left(k_{L} D\right)}{H_{v}^{(1)}\left(k_{L} b\right) \sin v \pi} J_{v}\left(k_{L} b\right) \mathrm{d} v \\
& I_{3}^{a}=i \int_{c} \mathrm{~B}_{2 v}^{02} \\
& \cdot \frac{J_{n+v}\left(k_{L} D\right)+(-)^{n} J_{n-v}\left(k_{L} D\right)}{H_{v}^{(1)}\left(k_{L} b\right) \sin v \pi} J_{v}\left(k_{T} b\right) \mathrm{d} v \\
& I_{1}^{b}=-i \int_{\mathcal{c}} \mathrm{B}_{2 v}^{\mathrm{e} 1} \\
& \cdot \frac{J_{n+v}\left(k_{L} D\right)-(-)^{n} J_{n-v}\left(k_{L} D\right)}{H_{v}^{(1)}\left(k_{L} b\right) \sin v \pi} H_{v}^{(1)}\left(k_{T} b\right) \mathrm{d} v \\
& I_{2}^{b}=-i \int_{c} \mathrm{~A}_{2 v}^{02} \\
& \text {. } \frac{J_{n+v}\left(k_{L} D\right)-(-)^{n} J_{n-v}\left(k_{L} D\right)}{H_{v}^{(1)}\left(k_{L} b\right) \sin v \pi} J_{v}\left(k_{L} b\right) \mathrm{d} v \\
& I_{3}^{b}=-i \int_{c} \mathrm{~B}_{2 v}^{\mathrm{e} 2} \\
& \cdot \frac{J_{n+v}\left(k_{L} D\right)-(-)^{n} J_{n-v}\left(k_{L} D\right)}{H_{v}^{(1)}\left(k_{L} b\right) \sin v \pi} J_{v}\left(k_{T} b\right) \mathrm{d} v \\
& I_{1}^{c}=i \int_{c} \mathrm{~A}_{2 v}^{\mathrm{e}} \\
& \cdot \frac{J_{n+v}\left(k_{T} D\right)-(-)^{n} J_{n-v}\left(k_{T} D\right)}{H_{v}^{(1)}\left(k_{T} b\right) \sin v \pi} H_{v}^{(1)}\left(k_{L} b\right) \mathrm{d} v
\end{aligned}
$$

$$
\begin{aligned}
I_{2}^{c} & =i \int_{c} \mathrm{~A}_{2 v}^{\mathrm{e} 2} \\
& \cdot \frac{J_{n+v}\left(k_{T} D\right)-(-)^{n} J_{n-v}\left(k_{T} D\right)}{H_{v}^{(1)}\left(k_{T} b\right) \sin v \pi} J_{v}\left(k_{L} b\right) \mathrm{d} v
\end{aligned}
$$$$
I_{3}^{c}=-i \int_{c} \mathrm{~B}_{2 v}^{02}
$$$$
\frac{J_{n+v}\left(k_{T} D\right)-(-)^{n} J_{n-v}\left(k_{T} D\right)}{H_{v}^{(1)}\left(k_{T} b\right) \sin v \pi} J_{v}\left(k_{T} b\right) \mathrm{d} v
$$$$
I_{1}^{d}=i \int_{c} \mathrm{~A}_{2 v}^{\mathrm{o} 1}
$$$$
\frac{J_{n+v}\left(k_{T} D\right)+(-)^{n} J_{n-v}\left(k_{T} D\right)}{-H_{v}^{(1)}\left(k_{T} b\right) \sin v \pi} H_{v}^{(1)}\left(k_{L} b\right) \mathrm{d} v
$$$$
I_{2}^{d}=i \int_{c} \mathrm{~A}_{2 v}^{02}
$$$$
\frac{J_{n+v}\left(k_{T} D\right)+(-)^{n} J_{n-v}\left(k_{T} D\right)}{-H_{v}^{(1)}\left(k_{T} b\right) \sin v \pi} J_{v}\left(k_{L} b\right) \mathrm{d} v
$$$$
I_{3}^{d}=-i \int_{c} \mathrm{~B}_{2 v}^{\mathrm{e} 2}
$$$$
\frac{J_{n+v}\left(k_{T} D\right)+(-)^{n} J_{n-v}\left(k_{T} D\right)}{-H_{v}^{(1)}\left(k_{T} b\right) \sin v \pi} J_{v}\left(k_{T} b\right) \mathrm{d} v
$$

(4) The Relation between the Beam-Width and the Horizontal Wave Number $k_{x}$ :

$$
k_{x}^{\prime \prime}=\frac{k_{z}^{2}}{k_{x}}\left[\frac{a^{2}}{z(h-z)^{3}}-\left(3+\frac{k_{z}^{2}}{k_{x}^{2}}\right) \frac{\tan ^{2} \varphi}{z^{2}}\right]
$$

wherein $\varphi$ is the polar angle in the coordinate system $O_{1}$ and $\sin \varphi=x / a$. The equation corresponding to beam-width is $k_{x}^{\prime \prime}(n, x)=0$, obtaining a quintic equation:

$$
a_{5} z^{5}+a_{4} z^{4}+a_{3} z^{3}+a_{2} z^{2}+a_{1} z+a_{0}=0
$$

wherein

$$
\begin{aligned}
& a_{5}=3 k_{2}^{2} \\
& a_{4}=-9 k_{2}^{2} h \\
& a_{3}=9 k_{2}^{2} h^{2}-4 k_{2}^{2} a^{2}-2 n^{2} \pi^{2} \\
& a_{2}=3 h\left(k_{2}^{2} a^{2}-k_{2}^{2} h^{2}+2 n^{2} \pi^{2}\right) \\
& a_{1}=3 n^{2} \pi^{2}\left(a^{2}-2 h^{2}\right) \\
& a_{0}=-2 n^{2} \pi^{2}\left(a^{2} h-h^{3}\right)
\end{aligned}
$$

\section{Data Availability}

The data used to support the findings of this study are available from the corresponding author upon request. 


\section{Conflicts of Interest}

The authors declare that there are no conflicts of interest regarding the publication of this paper.

\section{Acknowledgments}

This research is finally supported by the National Key Research and Development Plan (2018YFC1405900), the Key Project of National Natural Science Foundation (61631008), and the Special Fund for Basic Scientific Research Service Fees of Central Universities (heu10500170006).

\section{References}

[1] J. Gobat and C. Lee, "Acoustic navigation and communication for high-latitude ocean research," AGU Fall Meeting Abstracts, 2006.

[2] A. K. Morozov, L. Freitag, and S. Singh, "Underwater acoustic technologies for long-range navigation and communications in the Arctic," in Proceedings of the Undersea Acoustic Measurement Conference, 2011.

[3] G. Jin, J. F. Lynch, and R. Pawlowicz, "Effects of sea ice cover on acoustic ray travel times, with applications to the Greenland Sea tomography experiment," Journal of the Acoustical Society of America, vol. 94, no. 94, pp. 1044-1057, 1993.

[4] P. N. Mikhalevsky, A. B. Baggeroer, A. Gavrilov, and M. Slavinsky, "Experiment tests use of acoustics to monitor temperature and ice in Arctic Ocean," Eos, Transactions, American Geophysical Union, vol. 76, no. 27, pp. 265-269, 1995.

[5] P. N. Mikhalevsky, A. N. Gavrilov, and A. B. Baggeroer, "Transarctic acoustic propagation experiment and climate monitoring in the Arctic," IEEE Journal of Oceanic Engineering, vol. 24, no. 2, pp. 183-201, 1999.

[6] F. Desharnais, G. J. Heard, G. R. Ebbeson, D. J. Thomson, D. J. Schillinger, and R. Seyan, "Acoustic propagation in an arctic shallow-water environment," in Proceedings of the Oceans 2003 Marine Technology Society, Institute of Electrical and Electronics Engineers Conference, MTS/IEEE, pp. 10-17, USA, September 2003.

[7] H. Schmidt and T. Schneider, "Acoustic communication and navigation in the new Arctic - A model case for environmental adaptation," in Proceedings of the 2016 IEEE Third Underwater Communications and Networking Conference (UComms), pp. 14, Lerici, Italy, August 2016.

[8] L. Freitag, P. Koski, A. Morozov, S. Singh, and J. Partan, "Acoustic communications and navigation under Arctic ice," in Proceedings of the OCEANS 2012 MTS/IEEE Hampton Roads Conference: Harnessing the Power of the Ocean, IEEE, Hampton Roads, Va, USA, October 2012.

[9] L. Freitag, K. Ball, J. Partan, P. Koski, and S. Singh, "Long range acoustic communications and navigation in the Arctic," in Proceedings of the MTS/IEEE Washington, OCEANS 2015, IEEE, Washington, DC, USA, October 2015.

[10] L. Freitag, P. Koski, S. Singh, T. Maksym, and H. Singh, "Acoustic Communications under Shallow Shore-Fast Arctic Ice," in Proceedings of the OCEANS 2017 - Anchorage, pp. 1-5, IEEE, Anchorage, Alaska, USA, September 2017.

[11] L. Godinho, P. Amado-Mendes, and A. Pereira, "A Hybrid analytical-numerical model based on the method of fundamental solutions for the analysis of sound scattering by buried shell structures," Mathematical Problems in Engineering, vol. 2011, Article ID 710623, 22 pages, 2011.

[12] J. L. Fleming and J. Moser, "A fourier approach to model electromagnetic fields scattered by a buried rectangular cavity," Mathematical Problems in Engineering, vol. 2009, Article ID 937327, 22 pages, 2009.

[13] Q.-F. He, Q. Zhang, Y. Luo, and L. Sun, "Sinusoidal frequency modulation fourier-bessel series for multicomponent sfm signal estimation and separation," Mathematical Problems in Engineering, 2017.

[14] C. H. Lin, V. W. Lee, M. I. Todorovska, and M. D. Trifunac, "Zero-stress cylindrical wave functions around a circular underground tunnel in a flat elastic half-space: incident $\mathrm{P}$ waves," Soil Dynamics and Earthquake Engineering, vol. 30, no. 10, pp. 879-894, 2010.

[15] V. W. Lee and W.-Y. Liu, "Two-dimensional scattering and diffraction of $\mathrm{P}$ - and $\mathrm{SV}$-waves around a semi-circular canyon in an elastic half-space: an analytic solution via a stress-free wave function," Soil Dynamics and Earthquake Engineering, vol. 63, pp. 110-119, 2014.

[16] C. A. Davis, V. W. Lee, and J. P. Bardet, "Transverse response of underground cavities and pipes to incident SV waves," Earthquake Engineering \& Structural Dynamics, vol. 30, no. 3, pp. 383-410, 2010.

[17] J. Pumplin, "Application of sommerfeld-watson transformation to an electrostatics problem," American Journal of Physics, vol. 37, no. 7, pp. 737-739, 1969.

[18] M. L. Rumerman, "Increased accuracy in the application of the Sommerfeld-Watson transformation to scattering of acoustic waves from spherical shells," The Journal of the Acoustical Society of America, vol. 94, no. 5, pp. 2502-2509, 1993.

[19] M. L. Rumerman, "Increased accuracy in the application of the Sommerfeld-Watson transformation to scattering of acoustic waves from spherical shells," The Journal of the Acoustical Society of America, vol. 94, no. 5, pp. 2739-2750, 1993.

[20] W. Fan, G. Y. Zheng, and J. Fan, "Analysis of scattering wave from a water-filled cylindrical shell using Sommerfeld-Watson transformation," Technical Acoustics, vol. 28, no. 8, pp. 142-144, 2009 . 


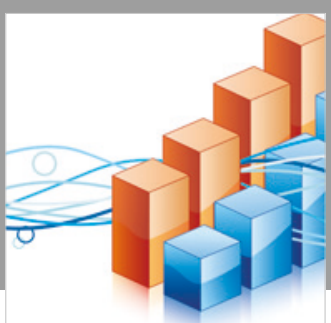

Advances in

Operations Research

\section{-n-m}
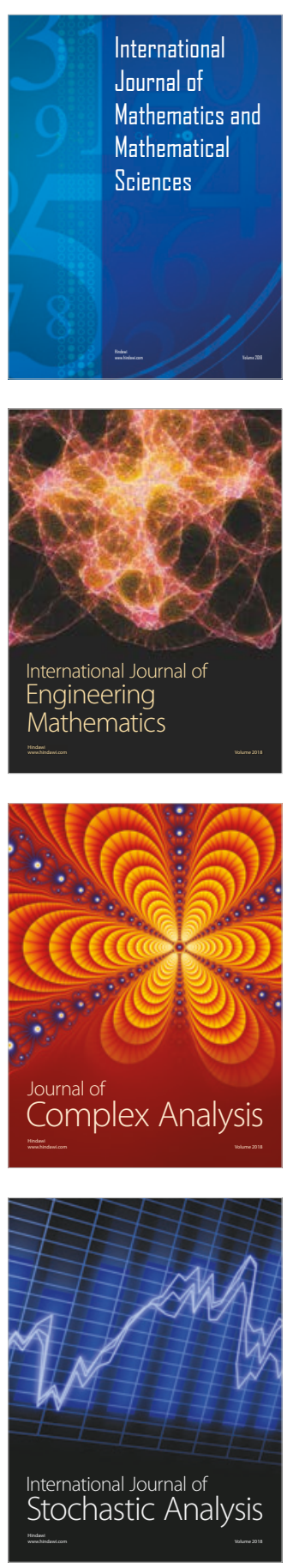
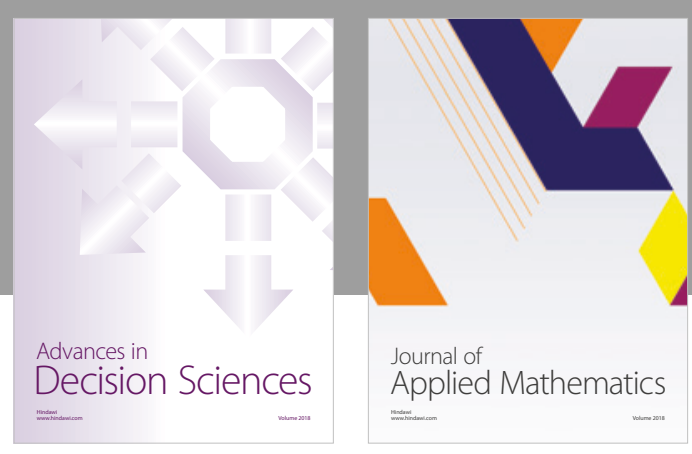

Journal of

Applied Mathematics
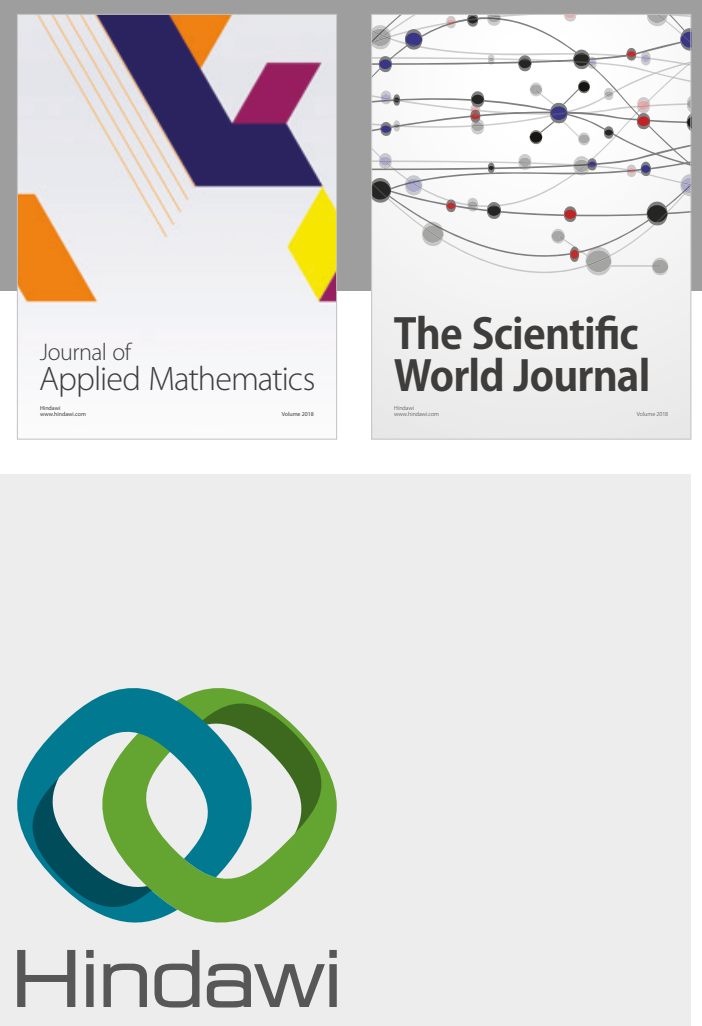

Submit your manuscripts at

www.hindawi.com

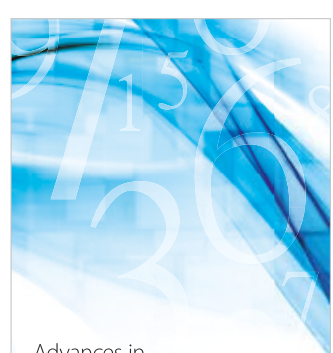

Advances in
Numerical Analysis
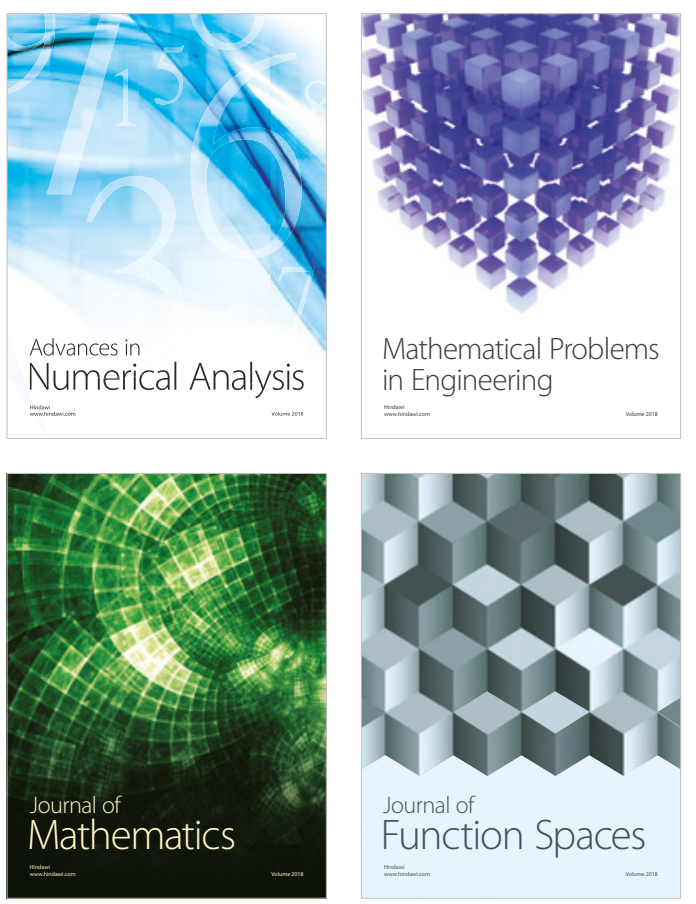

Mathematical Problems in Engineering

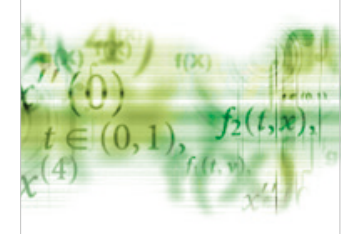

International Journal of

Differential Equations

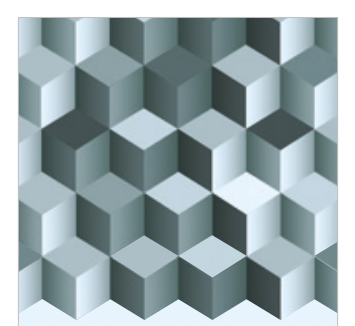

Journal of

Function Spaces

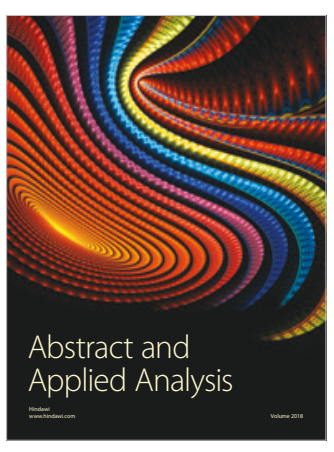

The Scientific

World Journal

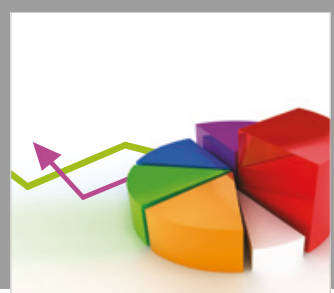

Journal of

Probability and Statistics
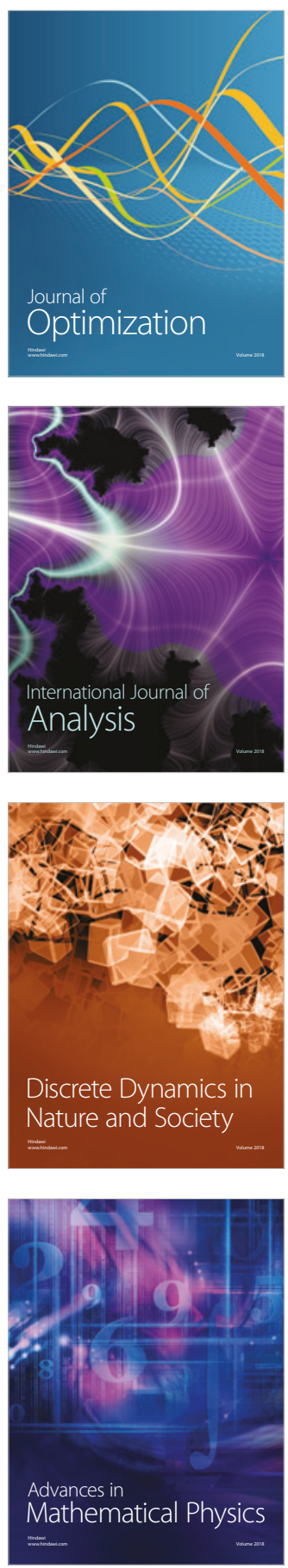